\title{
Rancang Bangun Alat Pembersih Pasir Silika Sebagai Penyaring Air Di PT. Tirta Fresindo Jaya
}

\author{
Rusdi Nur $^{1 *}$, Arthur H. Razak², A.Ari Putra ${ }^{3}$, Irsat Maulana ${ }^{4}$ dan Miftahul Ahmad ${ }^{4}$ \\ 1,2 Jurusan Teknik Mesin, Politeknik Negeri Ujung Pandang, Makassar 90245, Indonesia \\ *rusdinur@poliupg.ac.id
}

\begin{abstract}
This study aims to reduce the processing time for cleaning silica sand from 4 working days to 2 days. The first steps in designing this cleaning tool are the observation of the manual cleaning process and the shortcomings found in the work. Then design a cleaning tool that is better than the existing one. The next stage is planning, calculation and drawing to determine the components used. The last stage is production, printing and assembly. From the results of planning and calculations show that this silica sand cleaning tool is able to clean 30 $\mathrm{kg} / 4.25$ minutes or $425 \mathrm{~kg}$ / hour. The total cost required to make this tool per unit is Rp. 4,653,371.
\end{abstract}

Keywords: Design; Purifier; Water Filters; Silica Sand

\begin{abstract}
Abstrak: Penelitian ini bertujuan untuk mengurangi waktu proses pembersihan pasir silika dari 4 hari pengerjaaan menjadi 2 hari. Tahap-tahap dalam merancang alat pembersih ini yang pertama adalah pengamatan dari proses pembersihan manual dan ditemukan kekurangan dari pengerjaan tersebut. Kemudian perancangan alat pembersih yang lebih baik dari yang sudah ada. Tahap selanjutnya adalah perencanaan, perhitungan dan penggambaran untuk menentukan komponen-komponen yang digunakan. Tahap terakhir adalah produksi, pangecetan dan perakitan. Dari hasil perencanaan dan perhitungan menunjukkan bahwa alat pembersih pasir silika ini mampu membersihkan $30 \mathrm{Kg} / 4,25$ menit atau $425 \mathrm{Kg} / \mathrm{Jam}$. Biaya keseluruhan yang dibutuhkan untuk membuat alat ini per unit sebesar Rp. 4.653.371,--
\end{abstract}

Kata kunci : Rancang Bangun; Alat Pembersih; Penyaring Air; Pasir Silika

\section{PENDAHULUAN}

Pasir adalah material yang penting dalam bidang konstruksi bangunan, baik untuk bangunan rumah tempat tinggal, tempat ibadah, perkantoran, maupun gedung-gedung sarana pendidikan serta bangunan lainnya. Material ini selain digunakan dalam konstruksi bangunan, pasir juga berfungsi sebagai media dalam proses penyaringan air dimana jenis pasir yang digunakan yaitu pasir silika/pasir kuarsa. Pasir silika adalah jenis pasir khusus yang sangat sering digunakan pada filter (saringan) air karena sangat efektif dalam menjernihkan air yang keruh [1].

Penggunaan pasir silika dalam hal proses penyaringan air banyak digunakan pada industri, baik dalam industri makanan maupun minuman. Fungsi pasir silika atau biasa disebut pasir kuarsa atau pasir kwarsa ( $\mathrm{SiO} 2)$ adalah untuk menghilangkan kandungan lumpur atau tanah dan sedimen pada air minum atau air tanah atau air PDAM atau air gunung pada industri pengolahan air. Dalam hal ini pasir silika digunakan sebagai penyaring air sebagai bahan baku utama dalam pembuatan produk minuman.

Pasir silika disini berfungsi sebagai prefilter sebelum masuk ke tahapan saringan air berikutnya. Salah satu industri minuman yang menggunakan media pasir silika sebagai bagian dari proses penyaringan air yaitu PT. Tirta Fresindo Jaya. Sumber air baku yang selalu digunakan PT. Tirta Fresindo Jaya langsung dari sungai sehingga tidak menutup kemungkinan air baku tersebut tercampur dengan lumpur. Penggunaan pasir silika secara terus menerus lama kelamaan akan membuat lumpur hasil saringan akan menempel pada pasir, sehingga membuat proses penyaringan bekerja tidak maksimal. 
Hal inilah yang membuat pasir silika harus dibersihkan dalam jangka waktu tertentu. Pada PT. Tirta Fresindo Jaya memiliki sistem pencucian backwash dimana pasir dibersihkan dari lumpur dengan menggunakan mesin, namun penggunaan backwash ini sendiri terbatas karena jika jumlah lumpur yang menumpuk terlalu banyak dalam tangki menyebabkan backwash tidak maksimal. Sehingga pihak perusahaan melakukan pembersihan dengan cara manual. Pembersihan ini akan dilakukan jika pasir telah digunakan dalam jangka sekitar 6 bulan pemakaian atau bahkan lebih cepat bergantung pada kondisi sungai.

Berdasarkan hasil pengamatan dan sumber informasi yang kami peroleh dari salah satu karyawan yang bekerja di PT. Tirta Fresindo Jaya yaitu pencucian manual dilakukan dengan mengeluarkan pasir dari tangki penampungan menggunakan sekop, lalu diletakkan di wadah yang telah berisi air. Setelah pasir diletakkan dalam wadah kemudian pasir dibersihkan dengan cara mengaduknya dengan tangan, kemudian dilakukan penggosokan untuk memisahkan pasir dari lumpur.

Setelah itu air bekas pencucian yang kotor dibuang, lalu pasir dibilas kembali menggunakan air bersih, setelah pasir bersih dari lumpur, langkah selanjutnya pasir dimasukkan kembali kedalam tangki penampungan dengan menggunakan sekop. Adapun waktu yang dibutuhkan dalam membersihkan sejumlah pasir dengan berat sekitar $6000 \mathrm{~kg}$ dan memerlukan proses pencucian sekitar 4 hari atau 96 jam kerja apabila pengerjaan dilakukan 3 shift 24 jam dan membutuhkan tenaga kerja sebanyak 9 orang.

Melihat hal tersebut, proses pencucian ini memiliki banyak kekurangan dimana proses pencucian yang membutuhkan waktu yang lama dan biaya yang tidak sedikit, proses seperti ini pula membuat downtime cukup lama sehingga menjadikan proses produksi menjadi terhambat. Dengan melihat permasalahan tersebut diatas kami mencoba melakukan Rancang Bangun Alat Pembersih Pasir Silika Sebagai Penyaring Air di PT. Tirta Fresindo Jaya". Dimana alat ini diharapkan mampu memisahkan antara pasir silika dengan lumpur lebih cepat.

\section{METODE PENELITIAN}

\section{A. Waktu dan Tempat Pelaksanaan}

Proses perancangan, pembuatan serta pengujian alat pembersih pasir silika ini akan dilakukan dalam waktu kurang lebih 5 bulan, terhitung mulai Maret hingga Agustus 2018. Adapun tempat pelaksanaan proses tersebut adalah di Bengkel Mekanik dan Bengkel Las Jurusan Teknik Mesin Politeknik Negeri Ujung Pandang.

\section{B. Alat dan Bahan yang Digunakan}

Sebelum mengerjakan alat pembersih pasir ini, ada beberapa alat dan bahan yang akan digunakan pada Tabel 1 berikut.

Tabel 1. Daftar nama alat dan bahan yang digunakan

\begin{tabular}{|c|c|}
\hline Alat yang digunakan & Bahan yang dimanfaatkan \\
\hline $\begin{array}{l}\text { - Mesin las listrik lakoni } 900 \\
\text { - Mesin bor tangan } 1-13 \mathrm{~mm} \\
\text { - Tang rivet } \\
\text { - } \text { Obeng } \\
\text { - Mistar ingsut } 150 \mathrm{~mm} \\
\text { - Mistar baja } 300 \mathrm{~mm} \\
\text { - Kuas } 2 \text { inch } \\
\text { - Gerinda tangan } 4 \text { inch } \\
\text { - Kunci ring } 12 \mathrm{~mm} \\
\text { - Tang kombinasi } \\
\text { - Motor bensin } 6,5 \mathrm{hp} \\
\text { - } \text { Pompa air shimizu ps } 128 \text { bit }\end{array}$ & 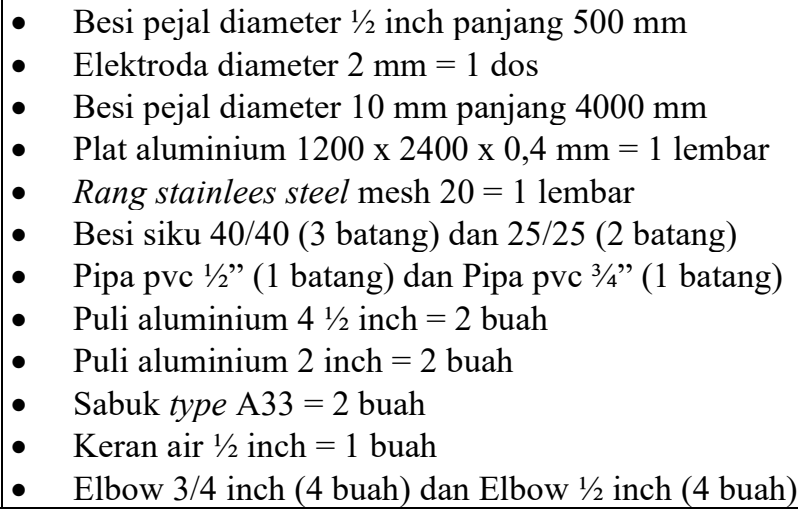 \\
\hline
\end{tabular}


54 Rusdi Nur, Arthur H. Razak, A.Ari Putra, Irsat Maulana, Miftahul Ahmad. Rancang Bangun Alat Pembersih Pasir Silika Sebagai Penyaring Air Di PT. Tirta Fresindo Jaya

- Helm las

- Siku $150 \mathrm{~mm}$

- Speed reducer type $501: 10$

- Gunting plat

- Palu besi

- Sarung tangan las
- $\quad$ Mata bor $4 \mathrm{~mm}, 6 \mathrm{~mm}$, dan $8 \mathrm{~mm}$ (1 buah)

- Plat strip $25 \times 4 \times 2000 \mathrm{~mm}=6$ batang

- Mata gerinda potong $4 \mathrm{inch}=10$ buah

- Mata gerinda poles 4 inch $=1$ bauh

- Baut mur M6 x 25 = 16 buah dan Paku keling $4 \mathrm{~mm}=1$

- $\quad$ Bearing p204 = 2 buah

\section{Tahap Perancangan}

Pada tahap ini akan dilakukan kegiatan rencana pembuatan alat berupa gambar desain setiap komponen [2] yang akan dibuat dan juga perhitungan perencanaan bahan dari pembuatan alat seperti perencanaan motor, reducer dan transmisi sabuk dan puli [3].

Dalam penentuan daya motor pada alat ini parameter yang kami gunakan adalah massa poros pencampur, massa pasir, massa air, dan massa puli yang akan digunakan. Jadi besarnya daya motor dapat dihitung dengan persamaan [4]:

$$
\mathrm{P}=\frac{\mathrm{Fs} . \mathrm{Vc}}{4500}
$$

$\mathrm{Fs}=$ Gaya yang bekerja pada poros $=\left(\mathrm{m}_{\mathrm{p}}+\mathrm{m}_{\mathrm{t}}+\mathrm{m}_{\mathrm{a}}+\mathrm{m}_{\mathrm{pl}}\right) \cdot g$

$=(2 \mathrm{Kg}+8 \mathrm{Kg}+2 \mathrm{Kg}+0,4 \mathrm{Kg}) \cdot 9,8 \mathrm{~m} / \mathrm{s}^{2}=121,6 \mathrm{~N}$

Dalam rancang bangun ini motor yang digunakan adalah motor bensin dengan putaran 2893 rpm dan diameter poros tabung $19 \mathrm{~mm}$, sehingga kecepatannya dengan persamaan berikut [5]:

$\mathrm{Vc}=\frac{\pi \cdot d s \cdot n}{\mathbf{1 0 0 0}}=\frac{3.14 \cdot 19 \cdot 2893}{\mathbf{1 0 0 0}}=172,596 \mathrm{~m} / \mathrm{menit}$

Berdasarkan data-data diatas maka daya motor yang digunakan adalah [5]:

$$
\mathrm{P}=\frac{\text { Fs . Vc }}{4500}=\frac{121,6 \cdot 172,59}{4500}=4.6 \mathrm{Hp}
$$

Daya motor yang dibutuhkan adalah 4,6 HP jika menggunakan motor listrik, namun motor yang kami gunakan yaitu motor bensin yang dijual dipasaran dengan kekuatan 6,5 HP atau lebih besar dari daya yang dibutuhkan. Alasan utama menggunakan motor bensin adalah dikarenakan cocok digunakan untuk menggerakkan poros tabung yang butuh variasi putaran yang tepat untuk produktivitas hasil pembersihan pasir serta mesin dapat digunakan ditempat yang belum dialiri aliran listrik.

\section{Kecepatan poros tabung penggerak}

Pada perhitungan kecepatan poros tabung penggerak kita mengambil dasar putaran poros tabung berkisar antara $50-60 \mathrm{rpm}$. Perhitungan ukuran puli untuk mencapai putaran tersebut adalah :

$\mathrm{P}=6.5 \mathrm{HP}, \mathrm{N}_{1}=2.893 \mathrm{rpm}, \mathrm{d}_{1}=50 \mathrm{~mm}$, dan $\mathrm{d}_{2}=112,5 \mathrm{~mm}$

Putaran poros transmisi dapat diketahui dengan menggunakan persamaan berikut [6]:

$$
\frac{N_{2}}{N_{1}}=\frac{d_{1}}{d_{2}}
$$

Maka : $\quad \frac{\mathrm{N}_{2}}{2.893}=\frac{50}{112,5} \rightarrow \mathrm{N}_{2}=\frac{114650}{112,5}=1285,7 \mathrm{rpm}$

Pada putaran 1285,7 rpm digunakan speed reducer dengan perbandingan 1: 10 sehingga putaran menjadi :

$$
\mathrm{N}_{1}=\frac{1285,7}{10}=128,5 \mathrm{rpm}
$$

Jika puli $3\left(\mathrm{~d}_{1}\right)=50 \mathrm{~mm}$

puli $4\left(\mathrm{~d}_{2}\right)=112,5 \mathrm{~mm}$,

$$
\text { Maka : } \quad \frac{\mathrm{N}_{2}}{128,5}=\frac{50}{112,5} \rightarrow \mathrm{N}_{2}=\frac{6245}{112,5}=57 \mathrm{rpm}
$$


Jadi putaran yang dihasilkan pada poros pembersih sebesar $57 \mathrm{rpm}$ dan dapat bertambah dengan menaikkan gas pada motor bensin.

\section{Tahap Pembuatan dan Perakitan}

Pada tahap pembuatan dilakukan pembuatan semua komponen yang akan digunakan karena tidak terdapat di pasaran. Adapun pada tahap perakitan akan dilakukan proses penggabungan tiap komponen sehingga membentuk suatu alat dengan mekanisme kerja yang sesuai dengan perencanaan sebelumnya. Tahapan ini meliputi:

a. Lakukan perakitan antara plat corong pasir dengan rangka corong dengan menggunakan paku keling yang telah dilubangi.

b. Kemudian satukan corong dengan rangka yang telah dibuat sesuaikan dengan gambar kerja, ikat dengan menggunakan baut M8 x $25 \mathrm{~mm}$ pada lubang yang telah dibuat.

c. Setelah itu, lakukan pemasangan wadah pasir pada rangka sesuai dengan gambar kerja. Proses penggabungan dilakukan menggunakan paku keling antara plat dan rangka pastikan tidak ada kebocoran pada wadah pasir.

d. Lakukan pemasangan bearing pada dudukan rangka yang telah dilubangi satukan dengan menggunakan baut M8 x $35 \mathrm{~mm}$ pastikan baut dikencangkan dengan erat.

e. Pemasangan tabung ayakan pasir dimana bearing didudukan pada rangka sesuai dengan gambar kerja dan diikat menggunakan baut dan mur M8 x $20 \mathrm{~mm}$. kemudian pada sisi lain roda dilas.

f. Pemasangan penggerak utama dan speed reducer pada rangkaian sesuai dengan gambar kerja, kemudian disatukan menggunakan baut dan mur M8.

g. Setelah motor penggerak dan speed reducer terpasang, lakukan pemasangan puli dengan ukuran 2 inci pada motor dan puli $4 \frac{1}{2}$ inci pada reducer pastikan posisi kedua puli sudah rata agar sabuk yang terpasangan dapat meneruskan putaran dengan bagus, lalu kencangkan baut pengikat puli dengan menggunakan kunci ring $12 \mathrm{~mm}$.

h. Setelah itu, memasang puli pada output reducer dengan ukuran 2 inci dan puli pada poros tabung dengan ukuran $4 \frac{1}{2}$ inci lalu disatukan kedua puli dengan sabuk tipe A33 pastikan kedua puli terpasang secara rata agar putaran dapat bergerak dengan baik, kemudian kencangkan baut pengikat pada puli dengan kunci pas $12 \mathrm{~mm}$.

i. Pemasangan pompa dan instalasi pompa pada rangka sebagai media aliran air. Dimana dipasang dua output dari pompa yaitu pipa pertama diletakkan dibagian bawah corong pasir dan pipa kedua dipasang pada sisi bagian luar tabung. Pipa yang digunakan adalah pipa ukuran $1 / 2$ inci dan diikat antara pompa dan rangka dengan menggunakan baut M8 x $25 \mathrm{~mm}$.

j. Terakhir pemasangan rangkaian saklar pada pompa air sebagai penghubung dan pemutus aliran listrik pada pompa air, hindari kontak langsung antara kabel dan rangka untuk meminimalisir resiko terjadinya korsleting listrik.

\section{E. Teknik Pengumpulan dan Analisa Data}

Dalam proses rancang bangun data pengujian merupakan suatu hal yang perlu diperhatikan, karena menjadi tolak ukur mesin yang akan dibuat, maka dari itu instrumen dan langkah-langkah pengujian harus diperhatikan.

Beberapa peralatan yang diperlukan dalam instrumen pengujian ini yaitu: Stopwatch, Tachometer 2,5 - $10.000 \mathrm{rpm}$, timbangan kapasitas $100 \mathrm{~kg}$, dan wadah penampung pasir $30 \mathrm{~kg}$. Adapun Bahan yang digunakan dalam pengujian ini yakni pasir silika sebanyak $30 \mathrm{~kg}$.

Setelah proses pembuatan dan langkah kerja telah dilaksanakan selanjutnya yaitu melakukan proses langkah pengujian yang bertujuan untuk menjawab dari tujuan dan manfaat penelitian dari alat yang dikerjakan:

- Sebelum melakukan pengujian pastikan semua bahan dan peralatan telah dipersiapkan.

- Siapkan pasir silika sebanyak $30 \mathrm{~kg}$. dan air sebanyak satu wadah atau 38 liter. 
- Menyalakan mesin bensin atur putaran mesin sesuai yang di inginkan dan ukur putaran menggunakan alat tachometer.

- Menyalakan mesin pompa air.

- Menyalakan stopwatch untuk mengetahui waktu pembersihan pasir.

- Setelah mesin penggerak dan pompa air on, masukkan pasir kedalam corong tabung secara terus menerus, pastikan untuk meminimalisir ceceran pasir yang jatuh dilantai.

- Mengamati waktu pembersihan pasir.

- Setelah semua pasir telah keluar dari tabung selanjutnya matikan mesin dan pompa air.

- Lakukan langkah pengujian 3 sampai dengan 7 sebanyak 3 kali sesuai waktu putaran yang telah di rencanakan.

- Mengambil pasir yang telah dibersihkan dari masing-masing putaran dan waktu pembersihan, kemudian melakukan pengujian secara visual untuk mengetahui apakah pembersihan pasir terjadi secara merata atau tidak.

Dalam pembuatan mesin pembersih pasir ini yang akan kami analisa yaitu putaran dan waktu pembersihan yang terbaik. Motor bensin sebagai penggerak dari alat yang akan digunakan sebagai mengganti prinsip kerja manual dari alat pembersih pasir tersebut. Dengan tenaga motor bensin yang digunakan dengan beberapa suku cadang yang inti digunakan diantaranya yaitu sistem puli dan sabuk sebagai pengantar atau memindahkan daya dari suatu tempat ke tempat yang lain agar dapat meratakan pemberian daya atau tenaga dan penggunaan bantalan sebagai dudukan dari tabung penyaring. Setelah itu lakukan langkah pengujian dan perbandingan untuk mengetahui tingkat efektifitas dari alat pembersih pasir dengan penggerak motor bensin, dan perbandingan tingkat produktifitas antara proses manual dan proses menggunakan alat yang kami buat. Lakukan sebanyak 3 kali pengujian untuk mengetahui kemampuan dari alat dan perbandingannya.

\section{HASIL DAN PEMBAHASAN}

\section{A. Hasil Perhitungan Biaya dan Pengujain}

Dalam proses pembuatan alat pembersih pasir silika ini, setiap komponennya akan melalui berbagai macam proses pengerjaan. Dari tahap tersebut kita akan mengetahui proses-proses kerja, biaya-biaya yang diperlukan dalam pembuatan mesin dan waktu pengerjaan dari setiap komponen sampai dengan perakitan.

Berdasarkan data biaya untuk memproduksi mesin pembersih pasir silika dapat diketahui dari jumlah biaya bahan langsung, biaya tenaga kerja dan biaya tidak langsung.

Tabel 2. Biaya manufaktur

\begin{tabular}{|c|r|}
\hline Biaya manufaktur & Harga (Rp.) \\
\hline Biaya bahan langsung & 2.901 .000 \\
\hline Biaya tenaga kerja & 1.296 .496 \\
\hline Biaya tidak langsung & 455.875 \\
\hline Jumlah & 4.653 .371 \\
\hline
\end{tabular}

Dilihat dari hasil perhitungan diatas telah diketahui biaya untuk memproduksi satu unit mesin pembersih pasir silika yaitu Rp. 4.653.371,-

Sebelum dilakukan pengujian hasil pembersihan, terlebih dahulu dilakukan pengujian awal untuk menentukan kapasitas pembersihan pasir yang dapat diolah dalam satu kali proses. Dalam hal ini diperhitungakan jumlah pasir yang akan masuk kedalah tabung pembersihan agar pada saat proses pengujian tidak membutuhkan waktu yang lama, dengan memperhatikan secara visual proses pergerakan tabung dan putaran motor yang paling baik, sehingga diperoleh kapasitas $30 \mathrm{~kg}$ untuk satu kali proses pengujian yang mana nanti hasil dari data ini akan dikalkulasi untuk menentukan jumlah keseluruhan pembersihan pasir. Selanjutnya dilakukan pengujian untuk menentukan kualitas hasil dan 
kapasitas pembersihan pasir dengan mencari putaran dan waktu pembersihan pasir terbaik untuk satu kali proses.

Terlebih dahulu mesin pembersih pasir dihidupkan, kemudian ukur putaran poros pengaduk menggunakan tachometer, selanjutnya dengan memasukkan pasir kedalam tabung pembersih dan dilakukan secara terus menerus. Dalam ini waktu dan hasil pemebersihan secara visual yang menetukan data mana yang akan digunakan. Perhitungan waktu dilakukan dengan menggunakan stopwatch. Berikut merupakan data pengujian dari tiga pengujian yang berbeda:

Tabel 3. Data hasil pengujian pembersihan pasir silika

\begin{tabular}{|c|c|c|c|c|c|}
\hline No & $\begin{array}{c}\text { Putaran } \\
(\mathrm{rpm})\end{array}$ & $\begin{array}{c}\text { Massa pasir } \\
(\mathrm{kg})\end{array}$ & $\begin{array}{c}\text { Waktu proses } \\
(\text { menit })\end{array}$ & $\begin{array}{c}\text { Kualitas hasil } \\
(\text { visual })\end{array}$ & $\begin{array}{c}\text { Kapasitas pembersihan } \\
(\mathrm{Kg} . / \mathrm{jam})\end{array}$ \\
\hline \multirow{2}{*}{1} & 3462 & 30 & 3 & Kurang bersih & 600 \\
\hline \multirow{2}{*}{2} & 2893 & \multirow{2}{*}{30} & 2,5 & Kurang bersih & 720 \\
\hline \multirow{2}{*}{3} & 2376 & \multirow{2}{*}{30} & 4,5 & Bersih & 450 \\
\cline { 4 - 6 } & & 7 & Bersih & 400 \\
\hline
\end{tabular}

\section{B. Pembahasan}

Dengan melihat tabel data pengujian diatas, proses pengujian dilakukan sebanyak tiga kali pengujian dimana pengujian ini dilakukan dengan membandingkan tiga putaran yang berbeda. Penilaian dari hasil pengujian ini dapat dilihat dari visual pada kebersihan pasir yang kedua dengan melihat waktu pembersihan guna membandingkan dengan pembersihan yang dilakukan secara manual, dimana dari ketiga pengujian ini diambil satu data putaran motor yang dapat dijadikan putaran dalam pembersihan pasir ini dilihat dari tingkat kebersihan dan waktu yang di gunakan.

Pengujian yang pertama dilakukan dengan menggunakan putaran motor $2376 \mathrm{rpm}$ dan massa pasir $30 \mathrm{~kg}$. data yang diapatkan waktu pembersihan yaitu 7 menit, maka perhitungan kapasitas pembersihan adalah $60 / 7 \times 30 \mathrm{~kg}=257 \mathrm{~kg} / \mathrm{jam}$ dengan kualitas pembersihan yang cukup bersih secara visual.

Pengujian yang kedua dilakukan dengan menggunakan putaran motor $2893 \mathrm{rpm}$. dan massa pasir $30 \mathrm{~kg}$. data yang diapatkan waktu pembersihan yaitu 4 menit dan 4,5 menit dengan perhitungan kapasitas produksi : $60 / 4 \times 30 \mathrm{~kg}=450 \mathrm{~kg} / \mathrm{jam}$ dan $60 / 4,5 \times 30 \mathrm{~kg}=400 \mathrm{~kg} / \mathrm{jam}$. Adapun rata rata waktu pembersihan 4, 25 menit, maka rata-rata kapasitas adalah $425 \mathrm{~kg} / \mathrm{jam}$.

Jadi rata rata waktu pembersihan 4,25 menit dengan kapasitas pembersihan yang dihasilkan yaitu 425 $\mathrm{kg} /$ jam dengan kualitas pembesihan yang cukup bersih secara visual.

Pengujian yang ketiga dilakukan dengan menggunakan putaran motor $3462 \mathrm{rpm}$ dan massa pasir $30 \mathrm{~kg}$. data yang diapatkan waktu pembersihan yaitu 3 menit dan 2,5 menit, maka diperoleh kapasitas produksi adalah $600 \mathrm{~kg} / \mathrm{jam}$ dan $720 \mathrm{~kg} / \mathrm{jam}$. Jika dirata-ratakan, maka waktu pembersihan 2,75 menit dengan kapasitas pembersihan $660 \mathrm{~kg} / \mathrm{jam}$ dengan kualitas pembersihan yang masih belum bersih. Adapun faktor yang mendasari pembersihan pada putaran ini tidak efektif karena putaran motor yang terlalu cepat sehingga pasir yang melewati tabung pembersihan akan bergerak lebih cepat juga, sehingga waktu papar pasir untuk penyemprotan air didalam tabung tidak terjadi secara efektif menyebabkan pasir keluar dari dalam tabung dengan keadaan kurang bersih. Dengan demikian setelah meninjau hasil pembersihan dengan melihat waktu dan visual pembersihan pasir dari ketiga pengujian ini, pengujian kedua dapat diambil sebagai putaran yang tepat dalam melakukan pembersihan pasir dengan alat ini, dimana data yang didapat yaitu kapasitas $425 \mathrm{~kg} / \mathrm{jam}$.

Penelitian yang dilakukan oleh Bagundol dkk untuk mengetahui efisiensi filter pasir lambat dalam pemurnian air sumur menggunakan pasir Sungai Labo sebagai pasir medium [7]. Filter pasir lambat bisa efektif untuk pemurnian air. Pembentukan "schmutzdecke" pada permukaan dasar pasir dapat memvariasikan efisiensi filter pasir lambat [7], [8]. 
58 Rusdi Nur, Arthur H. Razak, A.Ari Putra, Irsat Maulana, Miftahul Ahmad. Rancang Bangun Alat Pembersih Pasir Silika Sebagai Penyaring Air Di PT. Tirta Fresindo Jaya

\section{KESIMPULAN}

Berdasarkan pembahasan sebelumnya maka perancangan mesin pembersih pasir silika ini dapat disimpulkan bahwa waktu yang diperlukan dalam pembersihan menggunakan mesin pembersih pasir silika sebanyak $30 \mathrm{~kg}$ mulai dari pemasukan hingga pengeluaran pasir diperlukan waktu 4,25 menit atau kapasitas maksimum $425 \mathrm{~kg} / \mathrm{jam}$ atau untuk membersihkan pasir sebanyak $6000 \mathrm{~kg}$ hanya dibutuhkan waktu sekitar 14 jam yang jauh lebih efektif dibanding menggunakan manual yang membutuhkan waktu hingga 96 jam atau 4 hari kerja dengan kapasitas produksi hanya $62,5 \mathrm{~kg} / \mathrm{jam}$.

\section{UCAPAN TERIMA KASIH}

Ucapan terima kasih diberikan kepada pimpinan dan staf PT. Tirta Fresindo Jaya yang telah membantu dalam penelitian ini.

\section{DAFTAR PUSTAKA}

[1] C. V. Vedavyasan, "Sand Filter," in Encyclopedia of Membranes, 2016.

[2] G. T. Sato, "Menggambar Mesin Menurut Standar ISO, Cetakan ke-9, PT," Pradya Paramita. Jakarta, 2000.

[3] R. Nur and M. A. Suyuti, Pengantar Sistem Manufaktur. Deepublish, 2017.

[4] R. Nur and M. A. Suyuti, Perancangan mesin-mesin industri. Deepublish, 2018.

[5] S. R. Schmid, B. J. Hamrock, and B. O. Jacobson, Fundamentals of Machine Elements. 2014.

[6] P. Bhattacharyya, Machine translation. 2015.

[7] T. B. Bagundol, A. L. Awa, and M. R. C. Enguito, "Efficiency of Slow Sand Filter in Purifying Well Water," J. Multidiscip. Stud., 2013.

[8] T. A. Thomas and K. M. Kani, "Efficiency of Slow Sand Filter in Wastewater Treatment," Int. J. Sci. Eng. Res., 2016. 